\title{
Ensinar Conceitos em Ciências Contábeis
}

Teaching Concepts in Accounting Sciences

Enseñar Conceptos en Ciencias Contables

\section{Marcos Laffin}

Doutor em Engenharia de Produção pela Universidade Federal de Santa Catarina Professor do Programa de Pós-Graduação em Contabilidade da UFSC

Endereço: Rua das Cerejeiras no 186 Residência 4 - Carvoeira

CEP 88.040-510 - Florianópolis SC Brasil

e-mail: marcoslaffin@gmail.com

Telefone: +55(48) 3721-9383

Artigo recebido em 28/05/2014. Revisado por pares em 26/11/2014. Reformulado em 19/12/2014. Recomendado para publicação em 16/01/2015 por Sandra Rolim Ensslin (Editora Científica). Publicado em 29/05/2015. 


\title{
Resumo
}

Este estudo aborda as contribuições do mapa conceitual como forma de ensinar conceitos em Ciências Contábeis. O objetivo é compreender o uso deste recurso na diferenciação e reconciliação de conceitos visando à aprendizagem significativa e simultaneamente à reflexão sobre a prática pedagógica. No estudo foi utilizada a pesquisa bibliográfica, com base nas perspectivas de Ausubel (1980), Vygotsky (1993), Charlot (2000) e Contreras (2002), tendo como enfoque de que a aprendizagem é mediada pelo conjunto das relações sociais. Concluiuse que o ensino de conceitos em Ciências Contábeis a partir da aprendizagem significativa permite a ampliação dos saberes prévios dos estudantes. Essa possibilidade implica uma prática pedagógica intencional, a partir do desejo de aprofundar os conhecimentos contábeis e interdisciplinares na efetivação do trabalho do professor. De acordo com essa perspectiva o ensino de Ciências Contábeis poderá contribuir para uma sólida formação profissional e de participação cidadã.

Palavras-Chave: Ensino em ciências contábeis. Trabalho pedagógico. Mapa conceitual.

\begin{abstract}
This study discusses the contributions of the conceptual map as a way to teach concepts in Accounting Sciences. The goal is to understand the use of this feature in differentiation and reconciliation of concepts aiming at meaningful learning and simultaneously at the reflection on the pedagogical practice. In the study we used the literature, from the perspective of Ausubel (1980), Vygotsky (1993), Charlot (2000) and Contreras (2002), with the approach that learning is mediated by the set of social relations. It was concluded that the teaching of concepts in Accounting Sciences based on the meaningful learning allows the expansion of prior knowledge of the students. This possibility implies a deliberate pedagogical practice, from the desire to deepen the financial and interdisciplinary knowledge in the execution of the teacher's work. According to this perspective the teaching of Accounting Sciences can contribute to a solid and with citizen participation professional training.
\end{abstract}

Keywords: Accounting sciences teaching. Pedagogical work. Concept map.

\section{Resumen}

Este estudio aborda las contribuciones del mapa conceptual como forma de enseñar conceptos en Ciencias Contables. El objetivo es comprender el uso de este recurso en la diferenciación y reconciliación de conceptos buscando el aprendizaje significativo y simultáneamente a la reflexión sobre la práctica pedagógica. En el estudio fue utilizada la investigación bibliográfica, con base en las perspectivas de Ausubel (1980), Vygotsky (1993), Charlot (2000) y Contreras (2002), teniendo como enfoque de que el aprendizaje es mediado por el conjunto de las relaciones sociales. Concluimos que la enseñanza de conceptos en Ciencias Contables a partir del aprendizaje significativo permite la ampliación de los saberes previos de los estudiantes. Esa posibilidad implica una práctica pedagógica intencional, a partir del deseo de profundizar los conocimientos contables e interdisciplinares en la efectivización del trabajo del profesor. De acuerdo con esa perspectiva la enseñanza de Ciencias Contables podrá contribuir para una sólida formación profesional y de participación ciudadana.

Palabras Clave: Enseñanza en ciencias contables. Trabajo pedagógico. Mapa conceptual.

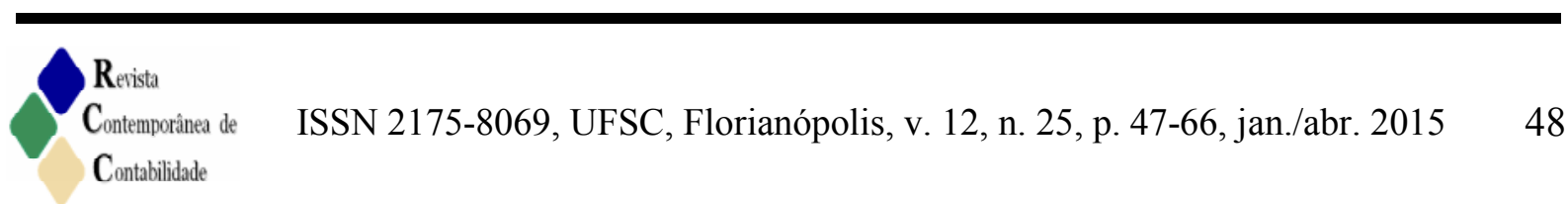




\section{Introdução}

Este texto envolve uma linguagem polissêmica. A polissemia é pensada na perspectiva de Bakhtin (2002), para quem a língua, na maneira de dizer as coisas, não se separa do seu conteúdo ideológico na compreensão da vida. Para Bakhtin (2002),

[...] não são palavras o que pronunciamos ou escutamos, mas verdades ou mentiras, coisas boas ou más, importantes ou triviais, agradáveis ou desagradáveis, etc. A palavra está sempre carregada de um conteúdo ou de um sentido ideológico ou vivencial (BAKHTIN, 2002, p. 95).

Com base nessa perspectiva, a polissemia utilizada neste texto envolve a linguagem com seu caráter ideológico, por meio da qual manifestam-se as experiências de base sóciohistórica e cultural no confronto com novas aprendizagens. Assim, o sujeito, e o que ele tem a dizer, é sempre de forma contextual e, desta forma, o dito pode ser compreendido como maneira de sociabilidade pois carrega a possibilidade de aprender com significados no contexto de pertencimento. Desta maneira, a polissemia neste texto corresponde aos diferentes sentidos pelos quais se propõe o desafio de pensar o que constitui as referências do mapa conceitual no ensino de Ciências Contábeis, concebido como um espaço de reflexão e participação nas relações constitutivas do trabalho docente e das ações de ensinar e aprender. Assim sendo, na estrutura deste texto anunciam-se as concepções epistemológicas do sujeito e dos conhecimentos envolvidos na mediação e nas relações da produção do trabalho docente. As concepções da prática pedagógica se insinuam como orientadoras das atividades desenvolvidas no universo particular do ensino em Ciências Contábeis.

A partir desse pressuposto, compreender o processo ensino-aprendizagem contextualizado exige interpretar as diferentes realidades dos conhecimentos, os propósitos do ensino, a composição dos conteúdos, a linguagem como possibilidade polissêmica, bem como o acolhimento ao sujeito que aprende. As relações de complexidade em que ocorre a prática docente demandam uma reflexão que delineia o produto do conhecimento contábil como intervenção social conjuntamente com uma reflexão sobre o fazer pedagógico de Ciências Contábeis, visando um reconhecimento do próprio ser e das concepções que ele assume no trabalho pedagógico.

Ensinar e aprender o conhecimento contábil requerem um percurso de disponibilidades para compreender a construção histórica e conceitual não apenas dos conhecimentos contábeis, como também dos conhecimentos pedagógicos. No ensino em Ciências Contábeis utiliza-se a estrutura de linguagem que fundamenta a elaboração da teoria contábil, a qual se constitui e articula em conceitos denotativos do pensamento contábil. Compreende-se que a aprendizagem de conceitos a partir dos saberes prévios dos estudantes de Ciências Contábeis permite ampliar esses saberes mediante as atividades intencionais das práticas de ensino.

Dessas premissas deriva uma problematização sobre as contribuições do uso da estratégia do mapa conceitual na aprendizagem de conceitos em Ciências Contábeis. Nesse sentido, foi estabelecido como objetivo compreender o uso dos mapas conceituais visando à aprendizagem significativa. Para Moreira (2012), a aprendizagem significativa ocorre quando:

[...] uma nova informação (conceito, ideia, proposição) adquire significados para o aprendiz através de uma espécie de ancoragem em aspectos relevantes da estrutura cognitiva preexistente do indivíduo, isto é, em conceitos, ideias, proposições já 
existentes em sua estrutura de conhecimentos (ou de significados) com determinado grau de clareza, estabilidade e diferenciação[...] (MOREIRA, 2012, p. 5).

Diferenciar conceitos é promover a inclusão de um novo conceito na estrutura cognitiva do sujeito. Essa diferenciação se dá pela relação entre os saberes prévios, já construídos pelas relações sociais, e o novo conhecimento que se deseja ampliar, de forma que os saberes prévios são fundamentais para ancorar novas e significativas aprendizagens. A integração de novos conceitos por meio dos saberes prévios favorece a atividade de diferenciação e reconciliação de conceitos.

A diferenciação de conceitos, na perspectiva da aprendizagem significativa, ocorre quando os saberes prévios são colocados em movimento, pois servem de base e permitem interagir com o novo conhecimento de forma a ampliar a aprendizagem prévia e ao mesmo tempo permitem diferenciar os significados do novo conteúdo.

Moreira (2012) enfatiza que

[...] os conceitos que interagem com o novo conhecimento e servem de base para a atribuição de novos significados vão também se modificando em função dessa interação, i.e., vão adquirindo novos significados e se diferenciando progressivamente (MOREIRA, 2012, p. 6).

A partir da integração e diferenciação de conceitos, processos mediados pelos saberes prévios, espera-se que, pela associação de ideias já estabelecidas na estrutura cognitiva, ocorra uma reconciliação integrativa de forma que se estabeleçam diferenças e semelhanças entre conceitos relacionados dando significado ao aprender. Moreira (2012) discorre sobre este processo dizendo que:

[...] Elementos existentes na estrutura cognitiva com determinado grau de clareza, estabilidade e diferenciação são percebidos como relacionados, adquirem novos significados e levam a uma reorganização da estrutura cognitiva. [...] essa reorganização cognitiva, esse tipo de relação significativa, é referido como reconciliação integrativa (MOREIRA, 2012, p.6),

Conhecer a realidade do trabalho do professor e dos estudantes de Ciências Contábeis para melhor compreender as situações caracterizadas por diferentes saberes, particularmente a partir dos objetivos discutidos neste texto, exige curiosidade em desvelar os fenômenos educativos - possibilidade que pode ser mediada pela atividade de pesquisa.

A pesquisa envolve tal curiosidade. No processo de conhecer, vislumbra-se a ressignificação de conhecimentos já adquiridos, uma vez que no percurso em busca de nova aprendizagem o conhecimento se expande na forma de alternativas adequadas ou soluções provisórias frente à problemática estudada. Dessa forma, a pesquisa é intencional, resultando em proposições para situações emergentes e muitas vezes recorrentes. Nessa perspectiva, a pesquisa constitui uma prática social porque se relaciona com fenômenos que ocorrem na esfera do coletivo a partir de uma realidade percebida, buscando novas formas de reelaborar o existente e assim responder ao contexto de demanda por meio da sistematização.

Neste estudo a pesquisa é constituída de curiosidade na forma de

[...] inquietação indagadora, como inclinação ao desvelamento de algo, como pergunta verbalizada ou não, como procura de esclarecimento, como sinal de atenção que sugere alerta faz parte integrante do fenômeno vital. (FREIRE, 1997, p. $35)$. 
Por meio dessa inquietação indagadora, visa à compreensão dos fenômenos e suas relações sociais e dos mapas conceituais na apropriação de conceitos no ensino em Ciências Contábeis, levando em consideração o universo contextual dos estudantes, da prática pedagógica, bem como dos conhecimentos socialmente constituídos.

A partir do diálogo entre concepções de sujeitos e conhecimentos nas relações sociais, busca-se desvelar práticas pedagógicas como práticas sociais que dialogam com o coletivo de saberes em sua pluralidade e particularidade.

Assim sendo, o diálogo coloca em movimento ideias e ações que constituem o produto do conhecer. Nessa perspectiva, entende-se que a pesquisa se constitui do diálogo entre o pesquisador e os diferentes autores que se manifestam sobre determinada problemática. Desse diálogo resultam subsídios e argumentos que contribuem para o desvelamento do objeto da pesquisa, os conhecimentos do pesquisador na apropriação de proposições, evidências do método em suas formas de pensamento e a produção da escrita na sua condição provisória de resultado da apropriação evidenciada pelo método como forma de pensamento. Nesse sentido, neste artigo assume-se a pesquisa bibliográfica com base nos elementos de historicidade, pluralidade e inacabamento dos sujeitos e seus conhecimentos em busca do conhecimento dos fenômenos em movimento.

A pesquisa bibliográfica é "desenvolvida com base em material já elaborado, constituído principalmente de livros e artigos científicos. Embora em quase todos os estudos seja exigido algum tipo de trabalho dessa natureza, [existem] pesquisas desenvolvidas exclusivamente a partir de fontes bibliográficas" (GIL, 2002, p 44). Compartilha-se tal concepção, uma vez que a inquietação indagadora requer ouvir e compreender as produções já elaboradas sobre o objeto que se pretende desvelar, no intuito de formular construtos e conhecimentos que melhor evidenciem os fenômenos que se deseja apreender. Neste contexto, o diálogo com os diferentes autores ajuda a confrontar as concepções e transitoriedade histórica do conhecer.

Segundo Severino (2002), a pesquisa bibliográfica objetiva a descrição conceitual e argumentativa a partir das obras escolhidas. A seleção criteriosa constitui a formulação do eixo temático que se articula com a perspectiva do pesquisador sobre o problema investigado. Portanto, a pesquisa bibliográfica, além de instrumentalizar o pesquisador, subsidia um acervo constituído de diferentes temas, autores e concepções sobre objetos de interesse e investigação.

Para instrumentalizar o caminho do conhecer, é preciso organizar e sistematizar a forma de pensamento para uma melhor apropriação das relações com o objeto de conhecimento. Este estudo, que tem como foco a estratégia do mapa conceitual, considera a aprendizagem um fator de desenvolvimento dos estudantes; logo, entende-se que as formas de aprendizagem são dinâmicas na subjetividade da condição humana e, portanto, requerem estudos no campo educacional.

A discussão sobre mapas conceituais no ensino de conceitos em Ciências Contábeis demanda uma apreensão dos diferentes elementos constitutivos do ensino em sua dimensão de conhecimento e prática social, requerendo, portanto um método para melhor apreender a sua ocorrência em contexto específico. Para Lüdke e André (1986),

Não existe um método que possa ser recomendado como o melhor ou mais efetivo. [...], pois é a natureza dos problemas que determina o método, isto é, a escolha do 
método se faz em função do tipo de problema estudado. (LÜDKE; ANDRÉ, 1986, p. $15)$.

Neste estudo, o método escolhido para conduzir ao diálogo com diferentes autores é o método dialético. A educação como fenômeno social reúne diferentes ideias sobre a sua forma de organização e objetivação e vincula-se sempre aos aspectos ideológicos, econômicos e sociais, afetando todo o contexto em que ocorre. Portanto, os estudantes, professores e conteúdos, bem como a aprendizagem, o ensino e as estratégias desse processo constituem o complexo fenômeno educacional sujeito à transitoriedade da história e dos sujeitos.

Para Meksenas (2002), a apreensão de conhecimentos da natureza e da condição humana é influenciada pelas relações sociais, de forma que o resultado dessa apreensão tornase um produto de conhecimento quando sistematizado. Para o autor, o método dialético permite extrair a compreensão das relações sociais estabelecidas a partir do confronto de realidades, pois:

Para obter o significado do fazer ciência em nossa sociedade capitalista, faz-se necessário o conhecimento das relações sociais de produção e de sua distribuição, isto é, das condições produtoras da riqueza e da miséria. (MEKSENAS, 2002, p.85).

Assim sendo, este estudo é orientado pela dialética como forma de interrogar e compreender os contrários nos movimentos da prática pedagógica e os conhecimentos envolvidos, bem como pelos diferentes diálogos entre as concepções teóricas. De natureza exploratória, este estudo utilizou a pesquisa bibliográfica para dialogar com os autores selecionados e suas proposições, no sentido de melhor compreender a formação histórica de conceitos, a estratégia do mapa conceitual na aprendizagem significativa de conceitos em Ciências Contábeis e suas relações com o conhecimento que se amplia nos saberes prévios dos estudantes.

O texto está estruturado a partir de uma apresentação dos conceitos fundantes da linguagem contábil (item 2), pelos quais delineia-se uma construção textual envolvendo extratos básicos da ciência contábil com a finalidade de articular os conceitos mais e menos inclusivos e, a partir dessa articulação, ampliar a relação entre os conceitos e a sua funcionalidade na estrutura conceitual teórico-prática. Os conceitos básicos inseridos nessa construção textual buscam evidenciar elementos formativos da diferenciação progressiva e da reconciliação integrativa dos conceitos estabelecendo elos de articulação na compreensão da estrutura da ciência. Com a construção textual que expressa um mapa conceitual, propõe-se ao leitor a sua reconstrução a partir de suas próprias experiências com os fundamentos da Ciência Contábil, desvelando, assim, a possibilidade de utilizar a estratégia na atividade do processo ensino-aprendizagem em Ciências Contábeis.

A partir da discussão sobre mapas da linguagem contábil (item 3), aborda-se um entendimento da mediação do ensino de acordo com a concepção de aprendizagem significativa por meio dos mapas conceituais. Pressupõe-se que os mapas conceituais sejam elaborados a partir de diagnósticos sobre o uso dos conceitos contábeis no cotidiano e que a sua reelaboração científica seja mediada pela prática pedagógica que incorpora às atividades de ensino o saber prévio, constituído como histórico no percurso das experiências dos estudantes.

No item (4) faz-se uma interlocução do conhecimento contábil com o ensino no sentido de evidenciar o trabalho do professor como uma prática social, desenvolvido a partir de processos intencionais, e que envolve, portanto, conhecimentos e sujeitos históricos com 
condições de questionar e contribuir para o desenvolvimento da ciência contábil por meio das interações sociais.

\title{
2 Conceitos fundantes da linguagem contábil
}

\begin{abstract}
A prática de ensino sem nenhuma relação com os contextos históricos, sociais e tecnológicos em que a ciência é constituída e aplicada, a ausência de fenômenos que possam mostrar a natureza das construções teóricas e dos modelos científicos como construções matemáticas e discursivas para interpretação e descrição da realidade muito mais complexa, tudo isso torna a ciência escolar algo desinteressante e sem sentido para a grande maioria dos estudantes. (MORTIMER, 1998, p. 114).
\end{abstract}

Reafirmando o que indica Mortimer (1998), aproximar os objetos de conhecimento da realidade dos estudantes é um desafio constante na transposição didática dos conteúdos de ensino. Tais conhecimentos, organizados nas disciplinas do currículo, constituem parte recortada da estrutura de conhecimentos de uma área de conhecimento. Também nos cursos de Ciências Contábeis, as disciplinas do currículo são recortes do conhecimento elaborado em sua busca de totalidade. O texto a seguir, elaborado por este autor, apresenta um conteúdo didático e precede a elaboração de um mapa conceitual. Como sugestão, o texto que segue utiliza termos e conceitos que favorecem a elaboração de um mapa conceitual em sua forma discursiva, articulando forma e conteúdo e construindo um percurso específico de caracterização geral da Ciência Contábil e seu funcionamento:

A Ciência Contábil é uma ciência classificada nas ciências sociais aplicadas. Tem por objeto de estudo o patrimônio das entidades físicas e/ou jurídicas, com finalidades lucrativas ou não. Infere-se assim que toda e qualquer entidade, seja em função do seu porte econômicofinanceiro, de sua finalidade ou de sua classificação jurídica, utiliza os conhecimentos da Ciência Contábil para administrar o seu patrimônio.

O patrimônio é tudo aquilo que pertence ou está sob o controle da entidade. A melhor forma de identificar um patrimônio é por meio de um inventário. Inventariar é descrever de forma quantitativa e qualitativa cada item que integra o patrimônio da entidade. A soma de todos os itens que pertencem ou são controlados pela entidade se constitui no valor do patrimônio que será posteriormente classificado e agrupado de acordo com a sua natureza e atributos. Esse inventário é sempre datado num dado momento do tempo. Em função da dinamicidade das entidades o patrimônio não é estático.

A Ciência Contábil irá evidenciar as variações que ocorrem no patrimônio. Como exemplo, citam-se as empresas, que precisam saber se obtiveram, em determinado período, uma evolução em seu patrimônio, ou seja, lucro. Assim, reunir dados e transformá-los em informações são as principais finalidades da Ciência Contábil, que desta forma assume importância para toda e qualquer entidade, desde a sua constituição até a sua dissolução.

Toda entidade é constituída por um capital inicial, denominado Capital Social, cuja fonte é proveniente dos proprietários. Por meio do registro, a Ciência Contábil produz informações sobre a origem de todos os recursos, como e onde eles foram aplicados na entidade. Deste modo, a Ciência Contábil pode fornecer o resultado da gestão bem como evidenciar o estado atual do patrimônio.

Os recursos podem ser provenientes de duas fontes: capitais próprios (aporte de proprietários e lucros gerados pela empresa) e de terceiros (aumento do endividamento). As 
informações contábeis, além de caracterizarem o estado atual do patrimônio, podem auxiliar na projeção de informações prospectivas de novos investimentos e decisões.

A partir do registro, por meio da escrituração contábil, são gerados relatórios informativos denominados Demonstrações Contábeis. Essas demonstrações informam a situação da entidade num determinado período e momento do tempo, além de evidenciarem o conjunto patrimonial da entidade que é expresso de forma quantitativa e qualitativa por meio das contas.

As Demonstrações Contábeis estão previstas na Lei $\mathrm{n}^{0}$. 6.404/76, e suas alterações substantivas - Leis $n^{0} 10.303 / 01, n^{0} 11.638 / 07, n^{0} 11.941 / 09$ - também conhecida como a Lei das Sociedades Anônimas, sendo as informações nelas evidenciadas para os usuários internos e externos. Ao registrar todas as operações da entidade (compras, vendas, entradas, saídas, pagamentos, recebimentos, direitos e obrigações) a entidade pode expor a situação líquida do seu patrimônio.

Ao proceder ao correto registro desses eventos contábeis, respeitando o período do exercício social, a entidade pode estabelecer comparações entre as mutações do seu patrimônio e a distribuição de seus resultados, além de fornecer aos usuários internos (administradores e gestores) e externos (sócios/acionistas, credores em geral, bancos, governo, fornecedores, clientes, etc.) informações sobre a situação do patrimônio administrado.

O exercício social é o período de tempo que a entidade utiliza para realizar o registro de suas operações e apurar o resultado do exercício, período em que são elaboradas e consolidadas as Demonstrações Contábeis. Conforme a Lei $n^{\circ}$. 6.404/76, um exercício social compreende um período de doze meses, exceto em ocasiões de constituição da companhia e em casos de alteração estatutária, quando o exercício social pode ter duração diversa, podendo o exercício social coincidir ou não com o ano-calendário. As demonstrações contábeis devem ser analisadas e interpretadas para que se possa comprovar a exatidão dos eventos realizados.

$\mathrm{O}$ registro de todas as operações é de fundamental importância para o controle do patrimônio. Esse registro é feito por meio da escrituração em livros próprios, obrigatórios e auxiliares, e segue a cronologia dos eventos, registrando os valores pelos quais são realizados com o mundo externo. Cada evento ou operação que ocorre na entidade e que movimenta o patrimônio é registrado em uma conta.

Conta é o termo técnico que se utiliza para cada um dos componentes do patrimônio e seu registro é individualizado e cronológico. É por meio do registro que se garante a igualdade nos valores das origens e das aplicações dos recursos da entidade. Essa igualdade de valores decorre da classificação dos elementos patrimoniais nos grupos do Ativo e do Passivo, sendo o total do Ativo igual ao total do Passivo.

No Ativo, são classificados os elementos patrimoniais que representam os bens e direitos controlados pela entidade, e no passivo são classificadas as obrigações pertencentes à entidade. A soma dos valores do ativo e do passivo representa o valor do patrimônio da entidade, e a igualdade da equação patrimonial evidencia a situação do patrimônio e também a situação líquida desse patrimônio, em que Ativo menos Passivo é igual ao Patrimônio Líquido (situação líquida ou capital próprio). Essa igualdade decorre do registro dos eventos por meio do método das partidas dobradas.

O método das partidas dobradas consiste no registro de cada evento contábil em, no mínimo, uma conta de natureza devedora e, em contrapartida, no mínimo em uma conta de natureza credora. Dessa maneira, o valor dos débitos sempre será igual ao valor dos créditos, 
o que ratifica o princípio da natureza das origens (de onde surgiram) e das aplicações (onde foram utilizados) dos recursos da entidade.

Para o registro das operações contábeis é possível fazer uso das fórmulas de lançamentos, utilizando-se vários débitos para vários créditos na escrituração, de forma que o valor total dos débitos sempre será igual ao valor dos créditos, indicando, assim, a natureza dos direitos e das obrigações da entidade, ou seja, de onde surgiram e para onde foram os recursos.

Para compreender a variação patrimonial, as mudanças que ocorrem no patrimônio de um exercício social para outro, o confronto de todas as receitas com todas as despesas demanda procedimentos de apuração do resultado do exercício - uma das particularidades do processo de escrituração que requer a observação de procedimentos técnicos e legais.

Para melhor utilizar os seus conhecimentos, as suas estratégias e funções, a Ciência Contábil organiza-se em especializações no interior do conhecimento, podendo ser utilizada na área gerencial, de custos, tributária, societária e ambiental, entre outras. Pelo detalhamento até aqui exposto pode-se inferir sobre a importância da Ciência Contábil para todos os tipos de entidades, sejam elas públicas ou privadas ou ainda organizações sociais de diferentes características e com distinta natureza jurídica, sendo a Ciência Contábil imprescindível para a gestão, controle e manutenção do patrimônio.

A partir destas reflexões sobre termos e conceitos básicos da Ciência Contábil é possível estruturar a proposição de ações de ensino por meio da estratégia de mapas conceituais. Tal proposta demonstra a diversidade do uso dos mapas conceituais, os quais poderão ser utilizados para apresentar conceitos, um conteúdo ou mesmo um corpo de conhecimentos com a finalidade de reconhecer aquilo que os estudantes já conhecem/dominam, visando estabelecer ações de estudo e de ensino para ampliar os conceitos/conteúdos na perspectiva da aprendizagem significativa.

\section{Mapas da linguagem contábil}

[...] A linguagem e a terminologia são exercícios intelectuais extremamente valiosos. O mesmo se dá com as definições e a delimitação de conceitos, pois ajudam a aprimorar o pensamento em contabilidade (HENDRIKSEN; VAN BREDA, 1999, p.84).

O sentido daquilo que se comunica em Ciências Contábeis pressupõe-se estar ancorado em denotação do pensamento contábil, contribuindo para que a função social da linguagem expresse o significado das palavras no contexto de sua intencionalidade e inserção. A comunicação do pensamento contábil ocorre por meio de diferentes subsídios da prática profissional dos instrumentos legais e de regulação que denotam as características da teoria da Ciência Contábil. Uma das expressões da síntese da comunicação contábil, a qual reflete um conjunto de informações, ocorre por meio das demonstrações contábeis, que evidenciam o momento e as perspectivas do patrimônio. Diante disso, a linguagem contábil utilizada comunica não apenas uma situação de patrimônio, mas substantivamente comunica também as denotações e apropriação do pensamento contábil.

A partir da premissa de que a linguagem contribui para o desenvolvimento do pensamento contábil, assume-se de forma contextualizada o pressuposto de que a comunicação exerce dinamismo e influencia as formas de apreender os fenômenos que 
ocorrem no mundo. A Ciência Contábil, sua base conceitual e as relações inerentes ao seu objeto de estudo são fenômenos culturais que ocorrem no mundo contemporâneo e sistematizam formas de conhecimento. Neste aspecto, a comunicação, em suas diferentes tipologias textuais, visuais, de oralidade e de escrita, traduz dimensões não apenas relativas à especificidade daquilo que representa como informação, mas também da cultura constitutiva dos objetos e fenômenos sociais nas formas de evidenciação.

No âmbito da apreensão dos fenômenos do mundo, é defensável a estruturação da linguagem conceitual aos diferentes procedimentos da apreensão do conhecimento contábil como ciência, estabelecendo relações de conhecimentos pelos significados que o uso da sua linguagem e intervenção produz na sociedade.

Uma das possibilidades de aproximação da linguagem e dos conceitos contábeis que traduzem normas e práticas profissionais, para iniciar e/ou aprofundar conhecimentos, encontra subsídios na estruturação de mapas conceituais que envolvem a diferenciação de conceitos e sua reconciliação integrativa. A utilização da estratégia do mapa conceitual no ensino em Ciências Contábeis é proposta como aproximação dos conceitos fundamentais da teoria e da prática contábil no sentido de apresentar e aprofundar as relações teórico-práticas da área com o universo contextual dos estudantes, bem como o ensino dos conteúdos como proposição inicial das aprendizagens na perspectiva de elaboração de significados.

Para Severino (2002),

\begin{abstract}
O conceito é a imagem mental por meio da qual se representa um objeto, sinal imediato do objeto representado. O conceito garante uma referência direta ao objeto real. Esta referência é dita intencional no sentido de que o conceito adquirido por processos especiais de apreensão das coisas pelo intelecto, que não vêm a propósito aqui, se refere a coisas, a objetos, a seres, a ideias, de maneira representativa e substitutiva (SEVERINO, 2002, p. 188).
\end{abstract}

De forma abrangente, os conceitos são os saberes ou as noções de conhecimento que por meio do ato de pensar as pessoas constroem sobre determinado objeto da realidade, atribuindo-lhe significado por meio de palavras, da linguagem.

Vygotsky (1993) faz uma diferenciação importante entre a construção cultural dos conceitos. Distingue conceitos espontâneos de conceitos científicos e aponta maneiras de compreender e utilizar essa forma de conhecimento. Para o autor, conceitos espontâneos possuem uma lógica difusa e particular e são construídos no dia a dia, enquanto conceitos científicos são elaborados a partir de estruturas lógicas do conhecimento e, portanto, não possuem uma estrutura pronta, requerendo assim uma capacidade de organizar as ideias para a sua compreensão.

Para Vygotsky (1993),

[...] o conceito não é simplesmente um conjunto de conexões associativas que se assimila com a ajuda da memória, não é um hábito mental automático, mas um autêntico e completo ato do pensamento (VYGOTSKY, 1993, p. 184).

Dessa forma, a utilização de conceitos passa a ser uma expressão de domínio das atividades intelectuais na interação com a realidade. Para Vygotsky, é na dimensão entre aquilo que o estudante já sabe e aquilo que ele ainda não domina que reside a mediação pedagógica, ou seja, os processos de intervenção do professor. Assim, a aprendizagem como atividade organizada favorece o desenvolvimento intelectual dos estudantes.

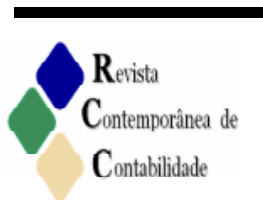

ISSN 2175-8069, UFSC, Florianópolis, v. 12, n. 25, p. 47-66, jan./abr. 2015 
No contexto do ensino de Ciências Contábeis, em que os estudantes trazem a sua experiência cultural por meio de conceitos espontâneos, espera-se, a partir do processo de ensino, a construção de percurso para os conceitos científicos pelos quais se evidencia a mudança da estrutura conceitual da qual se reveste o desenvolvimento psicológico dos sujeitos. A partir dessa perspectiva do sujeito e do processo formativo, os mapas conceituais podem ser utilizados nas atividades de ensino em Ciências Contábeis, constituindo estratégia utilizada para representar relações significativas entre conceitos, comumente relacionados aos princípios da aprendizagem significativa desenvolvida por Ausubel (1980):

Aprendizagem significativa é um processo pelo qual uma nova informação se
relaciona de maneira substantiva, não arbitrária e não literal a um aspecto relevante
da estrutura significativa do indivíduo. A nova informação interage com uma
estrutura cognitiva presente [...] (MOREIRA, 2006, p.15).

A aprendizagem significativa ocorre quando há interação ou reciprocidade em nível de diferenças com a estrutura cognitiva dos sujeitos estabelecendo relações com outros conceitos ou ideias já apropriadas, que subsidiam a compreensão e favorecem a aprendizagem de novos conceitos. Assim, o que influencia a aprendizagem de novos conhecimentos atua na relação que os sujeitos já construíram como saber prévio em sua estrutura cognitiva. Tais saberes irão favorecer novas e significativas aprendizagens a partir do reconhecimento do universo de saberes já apreendidos. Dessa forma, os saberes prévios tendem a servir de base para ampliar, ressinificar, estabelecer relações e diferenciar conhecimentos.

De acordo com essa concepção, um processo de ensino-aprendizagem no curso de graduação em Ciências Contábeis, que considera a realização de diagnósticos de saberes prévios dos estudantes sobre os conteúdos de ensino, tende a utilizar recursos que promovam a transposição dos conceitos fundantes da disciplina para as atividades de aprendizagem. Nesta acepção, os mapas conceituais são estratégias facilitadoras para a articulação dos conceitos básicos já existentes, bem como para a sua inclusão/ampliação na forma como os conhecimentos contábeis estão estruturados no ensino.

No contexto da aprendizagem significativa, a estratégia do mapa conceitual pode fazer uso de tipologias textuais, assim como construir gráficos, uma vez que favorece a interrelação de conceitos e possibilita a ampliação e apropriação de novos conhecimentos. Essa estratégia foi apresentada por Novak (1998) como possibilidade de aprender mediante o uso de conceitos em suas dimensões de diferenciação e de reconciliação integrativa. Segundo o autor, a diferenciação progressiva se caracteriza pelo desdobramento de outros conceitos, mantendo, no entanto, uma raiz orgânica em seus atributos.

Já a reconciliação integrativa favorece a conexão entre conceitos ainda não apreendidos. Ou seja, os atributos desses novos conceitos são inerentes aos conceitos mais gerais. Os mapas conceituais podem ser estruturados como estratégias de uma aula, de um determinado conteúdo ou como um conjunto de mapas conceituais que integrados constituem um corpo de conhecimentos com a intencionalidade de promover aprendizagens. A Figura 1 indica um diagrama de uma estruturação de esquemas passíveis de diferenciação e de reconciliação integrativa de conceitos.

Essa perspectiva de ensino indica que os mapas conceituais [...] "podem ser vistos como diagramas hierárquicos que procuram refletir a organização conceitual de uma disciplina ou parte de uma disciplina. Ou seja, sua existência é derivada da estrutura conceitual de uma disciplina. " (MOREIRA; MASINI, 1982, p. 45). Nesse sentido, são 
diagramas que estabelecem relações entre ideias ou conceitos, podendo ser utilizados como recursos metodológicos para organizar conhecimentos e processos de aprendizagem.

\section{Figura 1 - Representação do modelo de Ausubel}

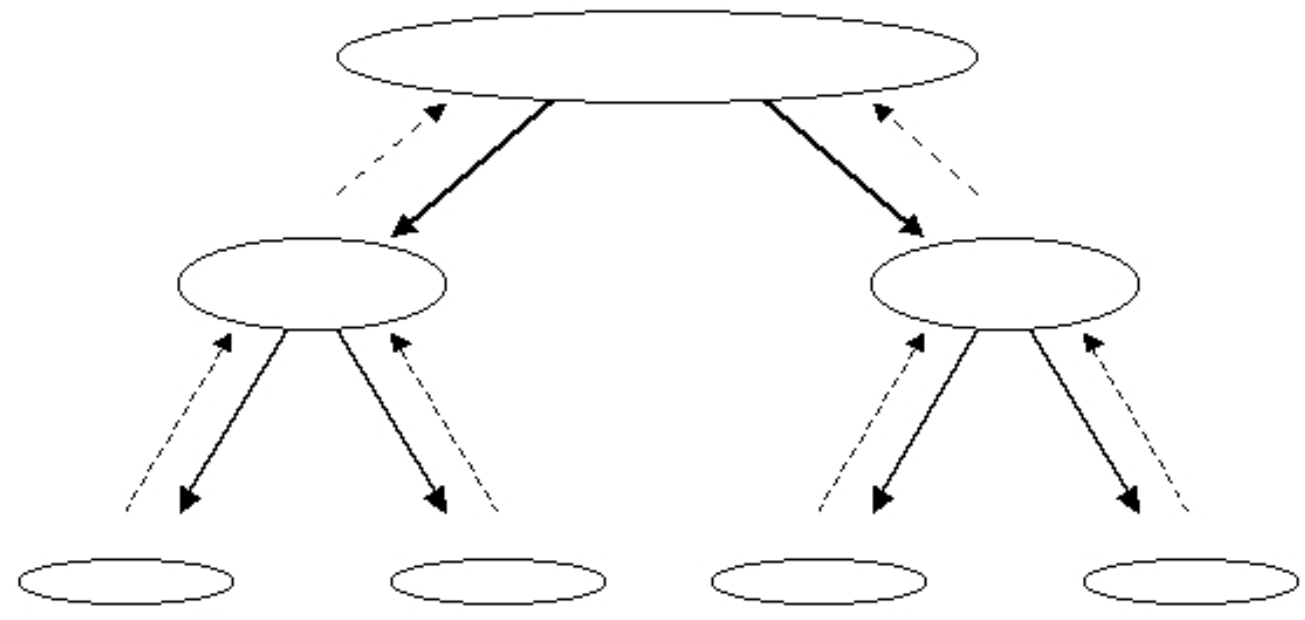

Fonte: MOREIRA e MASINI (1982).

Ainda de acordo com Moreira e Masini (1982, p. 45), os mapas conceituais podem ser unidimensionais e assim se apresentarem como "listas de conceitos que tendem a apresentar uma organização linear vertical”. Por outro lado, os mapas bidimensionais, quando expostos nas dimensões vertical e horizontal, "permitem uma representação mais completa das relações entre conceitos de uma disciplina." (MOREIRA; MASINI, 1982, p. 45). É importante ressaltar que os mapas conceituais, como possibilidade de representação concreta de uma estrutura conceitual, podem ser elaborados de diferentes maneiras para evidenciar uma hierarquia conceitual num diagrama.

Segundo Moreira e Masini (1982, p 46), [...] “o ponto importante é que um mapa conceitual deve ser sempre visto como 'um mapa conceitual' e não como 'o mapa conceitual' de um dado conjunto de conceitos". Portanto, um mapa conceitual elaborado a partir de um diagnóstico da realidade relativo à compreensão dos estudantes sobre o conteúdo, atende a certas especificidades do conteúdo da aprendizagem. Intrinsecamente a tal possibilidade, ao fazer uso desse recurso metodológico, o professor de Ciências Contábeis poderá organizar o conteúdo da disciplina conciliando os saberes prévios dos estudantes (LAFFIN, 2002, p. 10$11)$.

A proposição para utilização de mapas conceituais no ensino de Ciências Contábeis enseja a intencionalidade de uma sólida formação conceitual para uma correlação com a prática profissional diretamente vinculada aos conhecimentos contábeis. A utilização desse procedimento visando aprendizagens significativas possibilita não apenas a compreensão da Ciência Contábil no contexto no qual se insere, mas também a promoção do avanço do caráter de ciência da qual se reveste.

Nesse contexto, compartilha-se a ideia de Geraldi (2007), de que a linguagem se constitui em instrumento de comunicação quando é capaz de transmitir uma mensagem fundamentada numa forma de inter-ação por assumir um lugar de interação humana. Também 
Freire (2005) enfatiza a necessidade de reconhecer que o ensino se diferencia da atividade de transmitir conhecimentos, discutindo essa importância na perspectiva de identificar os condicionamentos do contexto sociocultural dos sujeitos implicados na aprendizagem de conhecimentos e valores culturais quando no acesso dos bens culturais produzidos. Ainda enfatiza que o professor precisa compreender e imprimir à sua prática pedagógica uma dimensão emancipatória, pois do contrário, o que poderá ocorrer é que:

\begin{abstract}
Em lugar de comunicar-se, o educador faz "comunicados" e depósitos que os estudantes, meras incidências, recebem pacientemente, memorizam e repetem. Eis aí a concepção "bancária" da educação, em que a única margem de ação que se oferece aos educandos é a de receberem os depósitos, guardá-los e arquivá-los. [...] Educador e educandos se arquivam na medida em que, nesta distorcida visão da educação, não há criatividade, não há transformação, não há saber. Só existe saber na invenção, na reinvenção, na busca inquieta, impaciente, permanente, que os homens fazem no mundo, com o mundo e com os outros. Busca esperançosa também (FREIRE, 2005, p. 6-7).
\end{abstract}

Ao considerar o estudante como sujeito de história e, portanto, de saberes que advêm da sua experiência de vida, busca-se atribuir significado contextualizado às aprendizagens, de forma a ressinificar a sua vida pela compreensão da consciência social que vai constituindo.

Assim, num diálogo entre a realidade existente e as possibilidades de reinventar uma condição libertária, mediado por conteúdos curriculares e suas práticas pedagógicas, o professor de Ciências Contábeis pode dimensionar também o seu trabalho como sujeito da intervenção.

Destaca-se que o contexto atual das organizações e das atividades da prática contábil demanda profissionais capazes de compreender o contexto no qual se inserem, de interpretar os fenômenos socioculturais e assim promover ações alternativas e viáveis às demandas de um mundo cada vez mais excludente. Ao recuperar a essência da epígrafe de Hendriksen e Van Breda (1999), utilizada no início do texto, enfatiza-se o propósito de reconstruir no processo ensino- aprendizagem em Ciências Contábeis as dimensões dos saberes prévios dos estudantes utilizando a polissemia dos termos e as transformações dos sentidos que assumem nos contextos específicos para, a partir deles, reconfigurar os objetivos da aula mediada pelos fundamentos da Ciência Contábil.

\title{
4 Interlocuções do conhecimento contábil com o ensino
}

Aprender é uma experiência social; o aprendizado ocorre através de interações com outras pessoas e de seu auxilio. Para passar dos objetos e ações para o campo dos significados, o aprendiz conversa com outras pessoas para expandir seu campo de entendimento. Durante o diálogo, ideias e experiências são compartilhadas e o aprendiz expõe seus problemas, gera hipóteses, conduz experimentos e reflete sobre os resultados (SCHUCK, 1997, p. 243).

Nas discussões até aqui realizadas, mediadas pela conversa com os diferentes autores, construiu-se um diálogo em defesa de práticas pedagógicas e de aprendizagem significativa concebidas como experiências das relações sociais. Assim, entende-se que no trabalho pedagógico do professor de Ciências Contábeis é imprescindível a articulação entre o discurso utilizado em suas atividades de ensino e a linguagem da Ciência Contábil. Para a interlocução 
desse processo é indispensável que o professor, em seu percurso de formação, busque conhecer diferentes práticas que poderá utilizar como formas de comunicação mais elaborada entre as relações sociais e o conhecimento contábil.

O professor, não apenas alguém que executa as atividades de ensino, mas que se constitui como sujeito histórico, que analisa crítica e reflexivamente suas atividades, deve buscar conhecer diferentes concepções do processo ensino-aprendizagem e, assim, ser capaz de apropriar-se, de sistematizar e de organizar uma concepção ampliada do conhecimento contábil e sua aplicabilidade, visualizando novas alternativas de organização curricular. (LAFFIN, 2005, p. 24).

Nesta mesma perspectiva, Contreras (2002) sugere ser necessário transcender o trabalho pedagógico para além dos limites da aula, do currículo, das exigências da instituição e impor processos de mudança no trabalho mediante um sentido político de opção na estrutura educacional visando uma autoridade incontestável de sujeito de cultura.

Para Contreras (2002),

Conceber o trabalho dos professores como trabalho intelectual. [é] desenvolver um conhecimento sobre o ensino que reconheça e questione sua natureza socialmente construída e o modo pelo qual se relaciona com a ordem social, bem como analisar as possibilidades transformadoras implícitas no contexto social das aulas e do ensino (CONTRERAS, 2002, p. 159).

Essa compreensão de professor de Ciências Contábeis como intelectual requer não apenas entender as circunstâncias do seu fazer pedagógico mas, a partir desse fazer, instrumentalizar novas ações voltadas para a condição humana e para os valores de solidariedade e igualdade, sem os quais apenas se especializa uma suposta prática sem, contudo, produzir mudanças significativas no mundo excludente.

Portanto, ao estudar as estratégias de ensino, faz-se necessário enfatizar a formação do professor de Ciências Contábeis e as suas concepções de trabalho pedagógico na utilização de recursos metodológicos visando à melhoria do ensino e formação profissional, bem como os significados do produto do seu trabalho. Enfatiza-se aqui a necessidade de compreensão do trabalho pedagógico, o qual é mediado pelos conhecimentos contábeis que imprimem um lastro de formação e consequente intervenção social pela prática contábil. Desse modo, é necessário que o professor tenha domínio do conhecimento contábil e, particularmente, dos conteúdos com os quais trabalha por representarem

[...] pontos básicos de sua ação profissional como agente da memória educativa em todos os tempos. Este domínio, no entanto, precisa ser compreendido não mais apenas como aquisição de seu acervo próprio de conhecimentos, mas também pela capacidade permanente do professor de questionar a sua relação com esse conhecimento, de refletir, de ir além. Neste sentido, colocar-se em estado permanente de aprendizagem é um aspecto estrutural da ação do docente (KENSKI, 2001, p. 98).

Neste contexto, uma alternativa sempre viável e subjacente ao trabalho do professor de Ciências Contábeis consiste nos processos de formação continuada, sobretudo a formação voltada para a docência. Isto porque o requisito mínimo da formação inicial e de sua formação em exercício, bem como de suas experiências no trabalho cotidiano, necessitam ser confrontados por pressupostos teóricos que contribuam com as demandas do cotidiano e da imprevisibilidade que constitui o trabalho docente como prática social. Uma possível 
interlocução entre os conhecimentos contábeis e as práticas de ensino requer não apenas o domínio dos conhecimentos com os quais trabalha mas, sobretudo, a partir desse trabalho, um constante questionamento sobre o conhecimento contábil produzido e as suas reais intervenções no mundo social. A formação continuada assume, assim, o seu espaço de formação na constituição da docência, por meio da qual o trabalho do professor é apreendido pelas relações sociais nas quais aprofunda a compreensão de si próprio, dos conhecimentos com os quais se humaniza e da realidade com a qual interage.

Ressalta-se, contudo, que na própria organização social e política da sociedade brasileira, em seu modelo excludente, também a formação constitui-se em mecanismo de valor e de mais-valia, ou seja, é preciso defender a integralidade e a qualidade dos processos de formação inicial para que a formação continuada assuma o status de formação plena, crítica e emancipatória e não de espaço para tornar-se produto de mercantilização em práticas educativas mais elaboradas, sem contudo promover mudanças significativas no ser e na sociedade.

$\mathrm{Na}$ interlocução do conhecimento contábil com o ensino faz-se referência à construção da teoria contábil como tendo sido constitutiva de um discurso coerente e de princípios lógicos que:

1. Oferece uma compreensão melhor das práticas existentes a contadores, investidores, administradores e estudantes.

2. Oferece um referencial conceitual para a avaliação de práticas contábeis existentes.

3. Orienta o desenvolvimento de novas práticas e novos procedimentos (HENDRIKSEN; VAN BREDA 1999, p.33).

Entende-se que no conjunto desses princípios que organizam referências da teoria contábil encontram-se indícios de compreender as práticas contábeis existentes no universo da autonomia patrimonial, uma vez que a ciência não é autônoma, pelo contrário, decorre da construção social de sujeitos contextualizados. Portanto, carrega em si a autonomia de melhor intervir como conhecimento de uso universal.

A partir desses princípios orientadores assume-se a possibilidade de interlocução do conhecimento contábil com o ensino em sua dimensão emancipatória, não fragmentada e substantiva, no percurso de formação dos estudantes e profissionais da área contábil. No conjunto dessas interlocuções e a partir da compreensão do trabalho do professor de Ciências Contábeis como trabalho apropriado, apresenta-se como relevante discutir os processos de aprendizagem, sobretudo no modelo de ensino contábil existente, a partir dos conceitos estruturantes da Ciência Contábil e das formas como o conhecimento contábil intervém na realidade existente.

Essa questão é bastante desafiadora, e ao mesmo tempo inquietante, quando nos encontramos inseridos num contexto educacional e intencionalmente comprometidos com a formação de nossos estudantes. Intencionalmente porque compreende a educação como trabalho no âmbito da teoria e da prática, na perspectiva da emancipação e da democracia social em que as construções universais são inalienáveis e de direito coletivo. A formação do estudante é aqui compreendida como produto de apropriação de novas situações de aprendizagem, nas quais novos conhecimentos e práticas são incorporados aos saberes já constituídos e em processo de elaboração por meio de processos de formação significativa.

Pensar a interlocução do conhecimento contábil com os processos de ensino requer pensar a aprendizagem no âmbito do trabalho docente. Isso exige um questionar constante 
sobre os objetivos educacionais, os conhecimentos e conteúdos escolares, os processos avaliativos, como situações indissociáveis da prática educativa. Assim, é possível entender a aprendizagem como a significação dos objetos humanos e suas relações constitutivas. A aprendizagem é, portanto, resultante da relação de significados entre as informações cognitivas acessadas e as construções de significados das novas experiências mediadas pela cultura humana. A aprendizagem possui um atributo individual decorrente da biologia humana e se internaliza no social pelo estabelecimento de significados e saberes mediados pelo mundo humano em suas relações culturais.

Considerando que esses princípios devam estar presentes no processo formativo do estudante de Ciências Contábeis, é possível compreender como e sob quais condições essas aprendizagens constroem relações de significados, bem como são estabelecidas pelo conjunto de atividades propostas e pela disponibilidade nas condições objetivas da aprendizagem.

No contexto das discussões e do diálogo aqui delineado é preciso refletir e interpretar quais são os desafios do processo ensino-aprendizagem para, então, questionar quais são os desafios da interlocução do ensino com o conhecimento contábil.

\section{Considerações Finais}

Há diferentes formas de se conceber o fenômeno educativo [...] Diferentes formas de aproximação do fenômeno educacional podem ser consideradas como mediações historicamente possíveis que permitem explicá-lo, se não em sua totalidade, pelo menos em alguns dos seus aspectos; por isso devem ser analisadas, contextualizadas e discutidas criticamente (MIZUKAMI,1986, p. 01).

Inicialmente, enfatiza-se a distinção dos objetos de investigação e interesse nos estudos de Ausubel, Vygotsky e demais autores desse diálogo. A utilização da perspectiva teórica desses autores baseia-se no entendimento de que ambos visualizam o processo de aprendizagem dos sujeitos como produto histórico e cultural. Ausubel afirma que aprender é atribuir sentido e significado ao conteúdo das aprendizagens, enquanto Vygotsky enfatiza que aquilo que o sujeito sabe e que não foi construído pela experiência não é realmente um saber. A aproximação da perspectiva teórica está na concepção de que a aprendizagem é um processo constituído de mediação - espaço de intervenção intencional do professor - na utilização de diferentes recursos que favoreçam a aprendizagem e contextualização de conhecimentos.

Nas discussões sobre os mapas conceituais como estratégias de ensino para favorecer a aprendizagem, eles são concebidos como instrumentos, não necessariamente se reduzindo a uma forma mecânica de ensinar. Isto por consistirem em mediação a ser realizada para promover os fins do ensino enfatizados neste texto, com a emancipação crítica dos sujeitos do processo ensino-aprendizagem.

A utilização dos mapas conceituais, assim como de outros recursos da atividade do professor, requer a compreensão e ação correspondente à sua concepção de sujeito, conhecimento e condição humana. De acordo com Geraldi (2007),

Antes de qualquer consideração específica sobre a atividade de sala de aula, é preciso que se tenha presente que toda e qualquer metodologia de ensino articula uma opção política - que envolve uma teoria de compreensão e interpretação da realidade - com os mecanismos utilizados em sala de aula (GERALDI, 2007, p.40). 
O trabalho de ensinar consiste na mediação entre o sujeito e o objeto de conhecimento, enquanto aprender consiste em estabelecer relações de significados entre um saber já apropriado e um novo saber. Para tanto, são necessárias ações diferenciadas: ensinar e aprender. Neste aspecto, a construção de um mapa conceitual dos saberes prévios dos estudantes de determinada disciplina no curso de graduação em Ciências Contábeis pode constituir um diagnóstico para o professor estruturar um plano de ensino.

Este estudo apresenta um mapa conceitual discursivo que deriva de um texto envolvendo conceitos básicos da estrutura do conhecimento contábil com a finalidade de instigar o leitor a elaborar mapas conceituais gráficos ou textuais visando ampliar o uso relacional dos conceitos fundantes da ciência contábil que permeiam o texto ao mesmo tempo em que possibilitam a ampliação e reconstrução dos referenciais delineados.

Para esse contexto, enfatiza-se uma perspectiva da prática pedagógica que se alicerça na perspectiva histórico-cultural na qual estudantes e professores são expressões das relações sociais pela relação dos percursos de experiências de vida. A possibilidade de reconstrução de si próprio e do outro é mediada por saberes plurais e inconclusos. A concepção de aprender de forma significativa articula-se à concepção de sujeitos históricos que interagem pela cultura com os conhecimentos que, por sua vez, também são assumidos como históricos e, portanto, inconclusos na dimensão humana. Corroborando essas considerações que evidenciam a complexidade dos sujeitos nas relações sociais, situam-se as contribuições de Charlot (2000), propondo uma importante reflexão sobre a relação social com o saber:

\footnotetext{
Queria lembrar, por fim, que "o mundo", "eu", e o "outro" não são meras entidades. "O mundo" é aquele em que [a pessoa] vive, um mundo desigual, estruturado por relações sociais. "Eu", o "sujeito", é um aluno que ocupa uma posição, social e escolar, que tem uma história, marcada por encontros, eventos, rupturas, esperanças a "ter uma boa profisssão", a "tornar-se alguém", etc. "O outro" são pais que atribuem missões ao filho, professores que "explicam" de maneira mais ou menos correta, que estimulam ou, às vezes, proferem insuportáveis "palavras de fatalidade". Não há relação com o saber senão a de um sujeito. Não há sujeito senão em um mundo e em uma relação com o outro. Mas não há mundo e o outro senão já presentes, sob formas que preexistem. A relação com o saber não deixa de ser uma relação social, embora sendo de um sujeito (CHARLOT, 2000, p.73).
}

Portanto, os sujeitos, ao se produzirem mediados pela linguagem constituída de subjetividades e contextos, são igualmente produtos que se constituem do outro pelas relações sociais. Dessa forma, a linguagem contábil, como estrutura do pensamento contábil e, portanto, da estrutura do sujeito humano, pode admitir a reconstrução do conhecimento contábil, uma vez que esse conhecimento se construa pela participação dos sujeitos no uso do conhecimento para a realização plena da condição humana.

Enfatiza-se que as preocupações e o diálogo aqui realizados não esgotam as discussões nem assumem um caráter prescritivo, mas apontam para questões vinculadas à realidade dos cursos de Ciências Contábeis no Brasil em relação à formação do professor, à sua participação na vida dos estudantes e à sua participação conjunta na sociedade. 
Referências

AUSUBEL, D.P.; NOVAK, J.D.; HANESIAN, H. Psicologia Educacional. Rio de Janeiro: Editora Interamericana, 1980.

BAKHTIN, M. Marxismo e filosofia da linguagem. São Paulo: HUCITEC, 2002.

CARVALHO. Ensinar a ensinar. São Paulo: Pioneira, 2001.

CHARLOT, B. Da relação com o saber. Elementos para uma teoria. Porto Alegre: ArtMed, 2000.

CONTRERAS, J. A autonomia dos professores. São Paulo: Cortez Editora, 2002.

FREIRE, P. Pedagogia da autonomia. Rio de Janeiro: Paz e Terra, 1997.

FREIRE, P. Pedagogia do oprimido. São Paulo: Paz e Terra, 2005.

GERALDI, J. W. O texto na sala de aula: leitura e produção. São Paulo: Ática, 2007.

GIL, A. C. Como elaborar projetos de pesquisa. São Paulo: Atlas, 2002.

HENDRIKSEN, E. S.; VAN BREDA, M. F. Teoria da Contabilidade. São Paulo: Atlas, 1999.

KENSKI, V. M. O papel do professor na sociedade digital. In: CASTRO E CARVALHO. Ensinar a ensinar. São Paulo: Pioneira, 2001.

LAFFIN, M. De contador a professor: a trajetória da docência no ensino superior de contabilidade. Florianópolis: Imprensa Universitária - UFSC, 2005.

LAFFIN, M. Ensino da Contabilidade: componentes e desafios. Contabilidade Vista \& Revista. Belo Horizonte, v. 13, $\mathrm{n}^{\mathrm{o}}$. 3, dez/2002.

LÜDKE, M.; ANDRÉ, M. E. D. A. Pesquisa em educação: abordagens qualitativas. São Paulo: EPU, 1986.

MEKSENAS, P. Pesquisa social e ação pedagógica. Conceitos, métodos e práticas. São Paulo: Edições Loyola, 2002.

MIRANDA, Gilberto José. CASA NOVA, Silvia Pereira de Castro. CORNACCHIONE JÚNIOR, Edgar Bruno. Os Saberes dos Professores-Referência no Ensino de Contabilidade. R. Cont. Fin. - USP, São Paulo, v. 23, n. 59, p. 142-153, maio/jun./jul./ago. 2012.

MIRANDA, Gilberto José. CASA NOVA, Silvia Pereira de Castro. CORNACCHIONE JÚNIOR, Edgar Bruno. A Pesquisa em Educação Contábil: Produção Científica e 
Preferências de Doutores no Período de 2005 a 2009. R. Cont. Fin. - USP, São Paulo, v. 24, n. 61, p. 75-88, jan./fev./mar./abr. 2013.

MIRANDA. Gilberto Jose. Docência universitária: uma análise das disciplinas na área da formação pedagógica oferecidas pelos programas de pós-graduação stricto sensu em Ciências Contábeis. REPeC - Revista de Educação e Pesquisa em Contabilidade, Brasília, v. 4, n. 2, art. 5, p. 81-98, mai./ago. 2010.

MIZUKAMI, M. G. Ensino: as abordagens do processo. São Paulo: EPU, 1986.

MOREIRA, M. A.; MASINI, E. F. S. Aprendizagem Significativa. A teoria de David Ausubel. São Paulo: Ed, Moraes, 1982.

MOREIRA, M. A. A teoria da aprendizagem significativa e sua implementação em sala de aula. Brasília: Editora UnB, 2006.

MOREIRA, M. A. Mapas conceituais e aprendizagem significativa. Disponível em: $<$ http://www.if.ufrgs.br/ moreira/mapasport.pdf $>$. Acesso em: 15 de maio de 2013.

MORTIMER, E. F. Sobre chamas e cristais: a linguagem cotidiana, a linguagem científica e o ensino de ciências In: CHASSOT, Attico (Org.). Ciência, Ética e Cultura na Educação. São Leopoldo: Ed. Unisinos, 1998.

NGANGA Camilla Soueneta Nascimento. BOTINHA, Reiner Alves. MIRANDA, Gilberto José. LEAL, Edvalda Araújo. MESTRES E DOUTORES EM SALAS DE AULA: ELES ESTÃO SENDO FORMADOS PARA ENSINAR? VIII Congresso Anpcont, Rio de Janeiro, 17 a 20 de agosto de 2014

NOVAK, J.D. Conocimiento e Aprendizaje: Los mapas conceptuales como herramientas facilitadoras para escuelas y empresas. Madrid: Alianza, 1998.

SCHUCK, G. Tecnologia inteligente, operários inteligentes: uma nova pedagogia para o local de trabalho high-tech. In: STARKEY, Ken. Como as organizações aprendem. São Paulo, 1997.

SLOMSKI, Vilma G. Saberes e competências do professor de Ciências Contábeis do Brasil. In: LOPES, J.; RIBEIRO FILHO, J. F.; PEDERNEIRAS, M. (Org.). Educação contábil: tópicos de ensino e pesquisa. São Paulo: Atlas, v. 1, p. 135 - 156. 2008.

SEVERINO, J. A. Metodologia do trabalho Científico. São Paulo: Cortez, 2002. VYGOTSKY, L. S. Obras Escogidas II: problemas de psicologia general. Madrid: Visor Distribuciones, 1993. 
